\title{
Raúl González Tuñón en el país del viento. Crónicas escritas y periodismo en el viaje a la Patagonia
}

\author{
Laura Juárez ${ }^{1}$
}

Resumen. El artículo analiza las crónicas periodísticas (nunca editadas en libro) que el poeta argentino Raúl González Tuñón publicó en el diario Crítica en 1932 como corresponsal viajero a la Patagonia Austral. Más allá de los objetivos explícitos y utilitarios del viaje del escritor propuestos por el diario (impedir que la Patagonia quede aislada por la supresión de una línea aérea nacional), se examina la complejidad de estas corresponsalías para estudiar las diversas formas enunciativas en las notas de González Tunón, la reescritura y apelación a saberes literarios y culturales sobre ese espacio geográfico, las elecciones ideológicas y estéticas en la construcción del itinerario del viaje y en las formas de la representación, y la intervención de denuncia y de contenido político y social que configura a la Patagonia como un espacio problemático, escenario permanente de crisis laborales y gremiales y terreno propicio para el conflicto obrero.

Palabras clave: Raúl González Tuñón; viaje; crónicas periodísticas; Crítica; Patagonia.

\section{[en] Raúl González Tuñón in the land of the wind. Written chronicles and journalism in the trip to Patagonia}

\begin{abstract}
The article analyses the journalistic chronicles (never edited for a book) published by the Argentine poet Raúl González Tuñón in the Crítica daily newspaper in 1932 as travelling correspondent to the Patagonia Austral. Aside from the explicit and utilitarian goals proposed by the daily for his journey (avoiding the isolation of the Patagonia region due to the removal of a national airline), we examine the complexity of the correspondent's work to study the varied forms of enunciation in González Tuñón's notes, the rewriting and the recourse to literary and cultural knowledge about this geographic area, the ideological and aesthetic selections in the design of the journey's itinerary and in the forms of representation; as well as the denunciating interventions, with political and social content, that shape the Patagonia as a problematic region, scene to permanent union and labour crisis, and a land prone to workers' conflict.

Keywords: Raúl González Tuñón; journey; journalistic chronicles; Crítica; Patagonia.
\end{abstract}

Sumario. 1. Introducción. 2. Representaciones. 3. El desierto productivo. 4. La ciudad ausente. 5. La Patagonia rebelde.

Cómo citar: Juárez, L. (2019) Raúl González Tunón en el país del viento. Crónicas escritas y periodismo en el viaje a la Patagonia, en Anales de Literatura Hispanoamericana 48, 299-313.

1 Universidad Nacional de La Plata/CONICET, La Plata. Argentina.

E-mail: laurasujuarez@gmail.com 
...yo te envío mi amor a doce grados bajo cero y la señorita del Correo no sabe nada, mientras los obreros,

ah, los obreros envejecen en los frigoríficos y las veletas,

ah, las veletas en los tejados rojos enloquecen

y en la calle ancha,

ah, en la calle ancha debe estar esperando la muerte

Patagonia 1932

(González Tuñón 1993: 161)

\section{Introducción}

En un ya clásico trabajo aparecido en el volumen de la Historia social de la literatura argentina dirigido por Graciela Montaldo, Isabel Stratta sostiene: "La pasión del viaje entra en la escritura de Tuñón antes como tópico literario que como dato de la biografía. El amor por 'los mares, los ríos y los puertos' está, en los primeros libros, al mismo nivel que su predilección por 'los rincones canallas y las mujeres perdidas" ". Y agrega: "Sólo hace falta la imaginación [...] poder vagar [...], y no es necesario cumplir con la verdad biográfica para decir 'yo tenía diez y seis años, y viajaba de polizón en los barcos" " (Stratta 1989: 188). Esto que Stratta señala y que se asume indefectiblemente como un tópico literario en su poesía, se vuelve más complejo, prolífico e inspirador en el viaje real y en los distintos recorridos por los que el autor ciertamente se desplaza. Tanto como viajero intelectual, escritor invitado a congresos internacionales y en calidad de enviado especial de diarios masivos como Crítica, González Tuñón en diferentes momentos recorre varios puntos del país y del extranjero y los textos allí surgidos entretejen múltiples modalidades del tópico literario (y también periodístico) del viaje enunciado por Stratta (testimonial, de denuncia, como cronista de prensa, político, turístico, etc.). ${ }^{2}$ La porosa y casi nula distinción entre los viajes reales y los imaginarios, la interferencia sustantiva entre ellos, la sutil, cualitativa y muchas veces aventajada distancia, y las similitudes o desencuentros entre esos trayectos efectivos y los inventados, puede decirse que constituyen marcas insistentes en su literatura y en su periodismo que la crítica nunca ha terminado de desandar, al menos en la intersección de los textos poéticos y las corresponsalías de prensa que refieren su experiencia de paseante y viajero intelectual.

Uno de esos viajes efectivos y concretos es el que realiza en 1932 a la Patagonia. Entre el 19 y el 24 de abril aparecen en el diario Crítica cuatro largos artículos periodísticos que González Tuñón firma como repórter viajero enviado

\footnotetext{
${ }^{2}$ Más allá del viaje a París que emprendió en 1929, pagado con el dinero del Premio Municipal de poesía, como corresponsal de Crítica, diario al que ingresó en 1925, realizó numerosos viajes al interior del país (a la Patagonia y a Tucumán para referir y documentar la vida de los cañeros) y al exterior como enviado especial. Por ejemplo, se dirige a la guerra del Chaco paraguayo y asiste como testigo del ascenso de Gertúlio Vargas en Brasil. También fue corresponsal de guerra de un diario republicano de Buenos Aires durante la Guerra Civil Española. Los siguientes viajes a Europa, el de 1935 y 1937, están marcados por las tensiones políticas, el ascenso del fascismo y aparece, como dice Stratta, un nuevo papel muy fuerte de "intelectual comprometido" (Stratta 1989: 189).
} 
por Natalio Botana al territorio de Santa Cruz. ${ }^{3}$ Sus notas se inscriben explícitamente en la particular empresa del diario, que intenta cubrir todos los frentes y que se expande también hacia el Sur argentino. ${ }^{4}$ Se enmarcan también en este propósito los textos enviados por Arturo Mom desde Comodoro Rivadavia, editados desde mayo de ese mismo año en el periódico. Las distintas corresponsalías se publican más o menos en paralelo desde abril a mayo de 1932, alternadas y sucesivamente en las páginas de Crítica: "El lejano Sur" se titulan las "impresiones" de González Tuñón, y "Oro líquido" las intervenciones de Arturo Mom, artículos centrados, estos últimos, casi exclusivamente en la cuestión petrolera y la riqueza de la zona. Según se manifiesta en la nota editorial que expresa los propósitos del diario, el objetivo del viaje del poeta es claro, y sus fines bien marcados y específicos: se trata de impedir que la Patagonia quede aislada por la supresión de la "línea aérea nacional al sud".

Bien en línea en un principio con lo propuesto por Crítica, el periodista viajero González Tuñón va a retomar un lema que rescata y cita de un diario de la zona y se propone como objetivo manifiesto no dejar que el desierto gane otra vez la Patagonia. Efectivamente, con una cierta reescritura y apelación a saberes literarios y culturales sobre ese espacio geográfico que se introducen sin mucha problematización (la Patagonia como un "desierto" vacío, bárbaro, en que puja una civilización ganada o conquistada) pero que se reconfiguran en las notas, como veremos, los textos de Tuñón se permiten justificar y explicitar por qué el Estado nacional debe mantener una línea aérea que asiduamente conecte ese territorio austral con el resto del país. Este es el motivo explícito en torno al que la argumentación periodística versará, más allá de las “impresiones” tomadas por el escritor en su trabajo de corresponsal en la Patagonia. "Raúl González Tuñón acaba de realizar por el lejano Sur un fecundo viaje de estudio y observación que le permitió recoger interesantes impresiones" (González Tuñón 1932a: 9. Énfasis mío), se afirma en el copete de Crítica.

El objetivo del viaje resulta en una primera mirada bastante instrumental y el tono predominante se articula claramente sobre la finalidad periodística de informar y difundir preanunciada por el diario. Ahora bien, más allá del registro informativo hábilmente desplegado y de ese propósito expreso del que González Tuñón en más de un sentido se hace portavoz, interesa revisar esas "impresiones" recogidas. $\mathrm{O}$, en otros términos, analizar la compleja escritura literaria, periodística y política que se inscribe sobre la intención más manifiesta de las corresponsalías. Esto permite leer los textos de González Tuñón en relación con ciertos tópicos y tradiciones escritas sobre el espacio argentino, el viaje y el extremo austral: aquellos que ya aparecen, como es sabido, desde el siglo XIX, como otros que los

\footnotetext{
${ }^{3}$ Estos textos nunca fueron recopilados en libro ni analizados hasta ahora.

${ }^{4}$ Para el diario Crítica véase el libro de Sylvia Saítta.

${ }^{5}$ En el artículo mencionado se lee lo siguiente: "Crítica destaca sus redactores a la Patagonia. Mientras Arturo Mom llega a Comodoro Rivadavia, tiene tiempo para despedir a Raúl González Tuñón, que regresa en avión de Río Gallegos después de haber recorrido la costa patagónica. Crítica, que sabe de la importancia que tiene y que tendrá con el tiempo la Patagonia inmensa y promisoria [...] [está] segura de realizar un bien impostergable: se trata de impedir que el desierto gane otra vez la Patagonia. Por lo pronto, mientras se habla de la supresión de la línea aérea nacional al sud, un redactor de Crítica comprueba el extraordinario beneficio que esa línea representa" (Crítica 19 de abril de 1932: 9). Un propósito similar anima, en principio, el viaje de Arturo Mom, que se presenta en Crítica como continuación del de González Tuñón.
} 
discuten posteriormente o que vuelven sobre ese territorio para desplegar, por ejemplo, ciertos modos de lo que podría denominarse como un ensayo de denuncia política y social. ${ }^{6}$ Aquí González Tuñón parece redoblar el objetivo inicial del diario y contribuir, en un plus de sentido que se suma a lo anterior, a la configuración de una identidad autoral asociada a una creciente politización, al afianzamiento de su compromiso social y a la lucha obrera o gremial (esta identidad se refuerza, como se sabe, en sus poemas y textos posteriores, de modos diversos).

Pretendo indagar, en este foco, las distintas formas escritas y enunciativas de estas notas de Crítica así como sus implicancias políticas. La reapropiación cultural y discursiva de un espacio de mezcla y problemático y los modos de representación. Los usos de la figuración poética urbana en la referencia a Río Gallegos y las visiones del sujeto itinerante. Estudiaré, en suma, las elecciones ideológicas y estéticas en la construcción del espacio del viaje y en las crónicas de González Tuñón. Las identidades escritas que allí se promueven, la intervención de denuncia y de contenido político y social, y cierta reutilización poética del viaje a la Patagonia en "Blues de Río Gallegos", el poema del libro posterior Todos bailan (1935), que permite pensar en reescrituras, pasajes, y en heterogéneas intersecciones entre el periodismo y la poesía.

\section{Representaciones}

Un territorio reiteradamente referido, creado e interpretado, la Patagonia constituye, como se sabe, uno de los espacios geográficos y culturales más incansablemente escritos y vueltos a escribir. El vacío ilusionado del desierto que la imaginación una y otra vez allí diseñó se colma, sucesivamente, de diferentes formas surgidas en disímiles momentos para proporcionar una cartografía y una realidad (por supuesto, imaginaria) a ciertas ilusiones culturales y espaciales que pugnan por llenar, reemplazar o modular lo existente. ${ }^{7} \mathrm{Si}$ la crónica funciona, por lo demás, como un tipo de texto que ofrece (pretende ofrecer) cierta versión de lo real ("insiste en lo real como una de sus características", "da una versión de lo real" —-sostiene Mónica Bernabé en una reflexión sobre el género-) (Bernabé 2006: 9), me interesa en un primer momento deslindar en qué sentidos es representado e imaginado ese espacio patagónico y vivenciado por el estar allí del cronista viajero: cómo aparece conformada esa realidad escrita o realizada (hecha realidad) en la disposición textual de las corresponsalías. Se trata de la representación del territorio de Santa Cruz y puntualmente la zona de Río Gallegos donde las notas se circunscriben, que en los textos se organiza, en un movimiento de sinécdoque (la parte reemplaza el todo) como la Patagonia entera. ${ }^{8}$ En la constitución de la

\footnotetext{
${ }^{6}$ Pienso, específicamente, en La Patagonia trágica, el texto de José María Borrero, publicado en 1928, que ha generado posteriores denuncias e investigaciones, como es el caso del libro posterior de Osvaldo Bayer, $L a$ Patagonia rebelde.

${ }^{7}$ Para la cuestión del desierto y el vacío puede consultarse el libro de Fermín Rodríguez. También, en relación con el viaje y el espacio patagónico, el de Ernesto Livon-Grosman.

${ }^{8}$ Lo mismo sucede en el ensayo de denuncia de José María Borrero, La Patagonia trágica. Aunque el texto se sitúa en Santa Cruz, la referencia se amplía a la Patagonia entera y constituye una caracterización de ese espacio como un todo.
} 
realidad de la crónica puede decirse que las notas producen una reapropiación discursiva sobre el territorio lejano, una operación que es tanto cultural como política, por la que González Tuñón pretende evitar (el objetivo manifiesto en la propuesta de Crítica) que la Patagonia se vuelva más lejana, y su territorio más vacío y más desierto con la supresión de la línea austral. Lo que amenaza entonces es la aparición de la barbarie (el desierto salvaje, despoblado y alejado de los centros), y el temor a desandar lo que aparece aquí como un camino de "progreso" y civilización:

La línea aérea a la Patagonia [...] fue comenzada a explotar hace más de dos años [...]. La creación de ese servicio trajo para la Patagonia, cuyo porvenir está en el aire, un beneficio incalculable. [...] Hoy se trata de suprimir ese servicio que está preparando el futuro patagónico. [...] ¿Qué son cien mil pesos de déficit que deja por año la línea a la Patagonia? [...] A medida que pasan los meses [...] la Patagonia siente que se acerca cada vez más a la civilización, a la actividad y al pensamiento del litoral...

[...] Pero un grito de angustia parece partir del corazón de la Patagonia. Es este, que encontramos en la primera página de un periódico del sud:

— "No dejemos que el desierto gane otra vez la Patagonia"

La supresión de la línea aérea [...] significaría el avance del desierto desnudo y salvaje, sobre el desierto cultivado y abierto a la explotación del hombre. Significaría la vuelta al trabajo trashumante, a la búsqueda del oasis casual, a la espera angustiosa de días y días, a la espera del resplandor que viene de las capitales, del norte, del centro civilizado de la República... Al renunciamiento, al fracaso, al éxodo, al abandono de la obra iniciada contra los elementos, contra la miseria, contra la explotación de las compañías extranjeras.

Crítica recoge el grito de angustia de la Patagonia argentina (González Tuñón 1932a: 9. Énfasis mío).

Con un tono que casi no reaparecerá luego, el escritor defiende el mantenimiento de la línea aérea (que contribuye a la causa "achicando la inmensa Patagonia") (González Tuñón 1932a: 9) y denuncia la ignorancia e impavidez del Estado nacional que está ausente en esta zona. El texto retoma con poco cuestionamiento tópicos situados en la tradición cultural y rubrica casi explícitamente la dicotomía civilización y barbarie (civilización opuesta a barbarie; desierto en oposición a progreso). También reescribe esa antinomia y llena de nuevos sentidos ese "desierto" bárbaro, vacío y "desnudo". Si no se mantienen las vías comunicacionales, la tierra "salvaje" podría_"ganar la Patagonia", quebrantar una cierta civilización conquistada y generar así, también, el "fracaso de la obra iniciada contra los elementos" (la naturaleza) y contra la explotación. Tuñón se refiere, claro, a la explotación de los trabajadores que denunciara, entre otros, José María Borrero, y a cuestiones que resuenan todavía después de más de diez años y que se remontan a las huelgas y sucesos trágicos de 1921 y 1922, que terminaron en la virulenta represión y matanza de obreros en manos del ejército (tema sobre el que volveremos). El cronista escritor parece ir aquí más allá de su propósito expreso y redobla la apuesta inicial al tocar un tema seguramente sensible para los 
lectores del diario. ${ }^{9}$ Efectivamente, en la denuncia social ligada al tema del fusilamiento obrero, su intención autoral se entrelaza, a su vez, con los supuestos intereses, gustos y afinidades del público asiduo de Crítica y con determinadas preferencias que ya había delimitado el diario un tiempo antes en relación con el denominado caso Kurt Wilkens. ${ }^{10}$

La representación del ámbito patagónico en la mirada de González Tuñón se organiza, en este sentido, en tres movimientos reconfiguradores de las opciones culturales reescritas anteriormente. Primero: la transformación del desierto "vacío" y por eso bárbaro y amenazante en tierra cultivada y promisoria. Segundo: la figuración en lo que se asume como la ciudad "lampiña" (desértica) existente, que es para González Tuñón Río Gallegos, de un cierto deseo (poético y textual) de la metrópolis ausente que es Buenos Aires o las grandes ciudades. Porque Río Gallegos es lo que la mirada situada en las urbes centrales como Buenos Aires le permite ser. Tercero: la delimitación y configuración cultural y política de la Patagonia como un espacio problemático, escenario permanente de crisis laborales y gremiales y terreno propicio para el conflicto social. En estos tres movimientos se deja de lado la mirada pintoresca y de tarjeta postal sobre la geografía natural. Dicha mirada, que fuera invocada reiteradamente en muchas de las representaciones del Sur argentino, y que podría decirse que se liga con la naturaleza monumental a la que convoca el territorio, ${ }^{11}$ en estas notas se relega al marco y a las fotografías que las acompañan. La intervención de la crónica se detiene, entonces, en "maravillas sin poesía" (González Tuñón 1932d: 11). Si hay paisaje, este es, como sostiene Graciela Silvestri a propósito de Sarmiento, una construcción paisajística que se vuelve política (Silvestri 1999: 221). ${ }^{12}$

\section{El desierto productivo}

En un tópico que retoma algunos de los lugares comunes de la literatura viajera y también de la crónica periodística, las corresponsalías de González Tuñón se

${ }^{9}$ Es interesante observar que las notas de Raúl González Tuñón como periodista enviado a la Guerra del Chaco boreal también van más allá de lo propuesto expresamente como objetivo de su viaje, pero en este caso sus textos discuten solapadamente la propuesta del diario en tanto defensora enfática de Paraguay. Véase, a este respecto: Juárez, 2015.

${ }^{10}$ Como sostiene Sylvia Saítta, “en abril de 1923, Crítica propone un pacto de lectura a través del cual se instituye en representante de los intereses populares, en 'la voz del pueblo' que encuentra en el caso Wilkens un acontecimiento clave que le permite exhibir demostraciones concretas de su imagen" (131). Como se sabe, Kurt Wilkens fue el anarquista alemán que asesinó al teniente Héctor Varela en venganza por la represión de los obreros de la Patagonia. Frente a la cobertura de los diarios La Nación y La Razón, que defendían la tarea de Varela y calificaban a Wilkens como un asesino, Crítica lo retrata como un héroe idealista. El hecho marca un antes y después en el diario, en la perspectiva de Sylvia Saítta. Véase "Wilkens", Crítica, 3 de febrero de 1923.

${ }^{11}$ Cierta mirada de tarjeta postal se inscribe, por ejemplo, en algunas zonas de las crónicas escritas sobre la Patagonia de Roberto Arlt, publicadas en el diario El Mundo en 1934.

${ }^{12}$ En una idea que explicita cómo se inauguraron algunos de los modos de la representación paisajística del espacio argentino, Graciela Silvestri sostiene que la novedad de las letras románticas, para el caso de Sarmiento y Humboldt, "radica [...] en la sintaxis de la imagen construida". Y explica: "en lugar de una suma de cuadros desconectados entre sí, Sarmiento [...] fija una imagen continua de diversos paisajes, les otorga valores morales y sentidos políticos. [...] En este sentido se conecta con la operación de Humboldt, cuya novedad no consistió en la mirada paisajística sino en la utilización del paisaje para nuevos fines científicos y políticos estrechamente enlazados" (Silvestri 1999: 220-221). 
inician con el relato del itinerario del escritor hasta el lugar de destino: es decir, con una minuciosa descripción del viaje en avión. En esa descripción, que arma un mapa del sitio patagónico a partir del vuelo en lo alto y se detiene en la enunciación de las marcas de la distancia y la lejanía (muestra todo el recorrido desde el cielo para revelar la necesidad de la línea aérea), se abandona explícitamente la representación del paisaje centrada en la carencia, el vacío y lo solitario, ${ }^{13}$ y el espacio se transforma en esperanza productiva; el desierto desocupado y amenazante en tierra explotada, en riqueza actual y prometida. Esto se vincula con el imaginario literario, científico y cultural del viaje a la Patagonia. Porque efectivamente, como señala Vanni Blengino, la Patagonia es y sigue siendo tierra de esperanza y rescate para el hombre. Promesa de futuro, oportunidades y riqueza, posibilidad de una existencia maravillosa, a estas caracterizaciones (que Blengino estudia a propósito de la Patagonia tal como aparece, por ejemplo, en El juguete rabioso y Los siete locos de Arlt) se suman aquellas que a la riqueza potencial anexan el deseo del progreso, "que exige ocupar en el menor tiempo posible el espacio llamado desierto" (Blengino 2005: 201). La lógica del progreso y ese imaginario se reactivan en González Tuñón y en sus textos se entrelazan los rastros reescritos "de la antigua mitología de Eldorado", cierta narratología científica, libresca y cultural, con "una Patagonia trágicamente realista" (Blengino 2005: 203) que es la de la explotación del hombre por el hombre. Esta última representación retoma los sucesos infaustos y amargos generados por las huelgas suscitadas desde 1921 y reenvía al conflicto presente de los trabajadores en 1932, que es denunciado enfáticamente por las crónicas.

Desde el vuelo en avión se puede ver entonces la configuración visual que ese sitio ofrece al ojo que observa y cómo se construye un territorio que ya no está tan vacío pero que puede estarlo si el Estado no se encarga de fortalecer los lazos económicos y comunicacionales. La percepción se desvía así del paisaje desértico y enfoca lo observado en su carácter de tierra explotada, cultivada y productiva; un espacio ocupado contrario al desierto que se vuelve promesa de futuro y civilización. "Patagonia inmensa y promisoria", como lo señala el propio escritor y poeta:

Cuando llegamos a Comodoro [...] desde el avión avistamos la cuenca del oro negro, el país del petróleo... ¡Petróleo! Lo único que, como dijimos un día, mueve al mundo junto con el amor. ¡Petróleo! ¡Oro líquido!

Toda una región riquísima que surge de una casualidad. [...] El espectáculo es raro, desconocido, hermoso. Pirámide tras pirámide sobre los pozos abiertos, ganados a las entrañas de la tierra privilegiada, más de mil doscientos pozos surgen a nuestra mirada bajo el cónico armazón de hierro. Un país. Una ciudad

13 "Es magnífico, inolvidable, el espectáculo de un vuelo a la Patagonia. [...] Río Colorado, Río Negro, [...] vestíbulo promisor del Sur lejano y misterioso... Después los desiertos inacabables del Chubut, y, en medio, junto al Río Chubut, en Trelew, la zona de las manzanas enormes y de los sabrosos quesos: los valles chubutanos, alargados y frescos en el corazón de la Patagonia. Y otra vez los desiertos, los ríos, la distancia desnuda, los médanos, las colinas peladas, las llanuras solo pobladas por guanacos y ovejas, y todo este panorama hasta más allá, hasta más allá de los bañados y las salinas de Santa Cruz, hasta el límite de Tierra del Fuego... Pero algo grande en todo: algo terrible y duro, un reclamo de máquinas y hombres blancos, una urgencia de futuro bien realizado, bien cumplido, para gloria de toda la República, cuyo porvenir, sin duda, está en la Patagonia..." (González Tuñón 1932a: 9). 
de hierro y de petróleo. Cuando descendimos del avión, cuando, durante una tarde entera caminamos por el país del petróleo la emoción es más viva y más pura: estamos en un pueblo donde exclusivamente se trabaja. Solo vemos pozos, galpones, usinas, destilerías, talleres, obreros, trajes azules, camiones, chimeneas, humo, caminos: solo vemos una película norteamericana, dinámica, diversa, amontonada y sonora, solo olemos petróleo, petróleo, petróleo... Y más tarde el pueblo de cinc y madera de la zona de YPF: una calle del Far West, pintoresca y colorida. Luego, entre cerro y cerro, entre el cerro Chenque y el cerro Vitau, el otro pueblo, el otro Comodoro Rivadavia, nacido a la sombra de las pirámides de hierro, y en donde galeses, escoceses, boers, yugoeslavos, españoles, italianos y argentinos, están haciendo de la raza patagónica, una raza vital y actual apta para la hora mecánica que vive el mundo... (González Tuñón 1932a: 9).

González Tuñón retrabaja caracterizaciones previas a la vez que viene a sostener el porvenir de la inmensa Patagonia. Es la tierra explotada y laboriosa lo que se percibe ahora como paisaje "hermoso" y "espectáculo" estético que se ofrece a quien lo mira como a un espectador. Con una postura ciertamente "entusiasmada", la percepción modulada por ese ojo que observa, se detiene en las formas diversas del trabajo y en la explotación de la tierra; en la riqueza del espacio y en su carácter promisorio y potencial. Una visión que estiliza los pozos petrolíferos y la mano de obra obrera y que descubre allí, en la tierra productiva, una escena "pintoresca" y cinematográfica, colorida y sensorial. ${ }^{14}$

En la cuestión de la riqueza, a propósito de ese territorio parcialmente explotado pero promisorio, importa considerar la denuncia del cronista sobre la escasa acción de los gobiernos, que con una buena "Dirección de Tierras, harían de la Patagonia el soñado paraíso de la riqueza nacional". González Tuñón vuelve acá sobre un tema consignado una y otra vez en las representaciones de ese espacio y que ya está inscripto desde fines del siglo XIX, por ejemplo, en La Australia argentina de Roberto Payró. Porque del mismo modo que en el texto de Payró, más que la lejanía geográfica es la ausencia del Estado lo que ocasiona los problemas en el Sur; motivos por los que el escritor-periodista va a demandar la necesaria presencia del gobierno nacional para el fortalecimiento de esa "tierra de esperanza": "un reclamo de máquinas y hombres blancos, una urgencia de futuro bien realizado, bien cumplido, para gloria de toda la República, cuyo porvenir, sin duda, está en la Patagonia" (González Tuñón 1932a: 11). O como afirma enfáticamente hacia el inicio de las notas: "La fauna patagónica es otro renglón importante de la riqueza solo parcialmente explotada y en forma lamentable, del lejano sud, latitud de hombres blancos y activos, silenciosos y trabajadores que esperan la ayuda de los gobiernos. Nuestro Canadá necesita los medios y las leyes

\footnotetext{
${ }^{14}$ En la primera de las crónicas, refiriéndose a la región santacruceña, González Tuñón agrega: “Todo puede darse en la Patagonia, y eso lo vamos comprobando a medida que dejamos atrás Comodoro, Deseado, San Julián, Santa Cruz [...] La fauna patagónica es numerosa y diversa. Hemos visto una cantidad enorme de guanacos. Los pequeños son riqueza. De ellos se hacen los guillangos. Las curiosas 'tribus' de lobos marinos también son riqueza: se aprovecha la grasa y la piel. Hay, cerca de las cordilleras muchos zorros grises y colorados y otros animales de gran valor. Las ballenas, ballenatos y cachalotes, ballenas grises del golfo de San Jorge, son riqueza. Ya es sabido que rinden un cien por cien" (González Tuñón 1932a: 9).
} 
propias para desarrollarse y responder a la esperanza de los que sabemos cuánto representará en el fututo del país" (González Tuñón 1932a: 9). ${ }^{15}$ Se trata, una vez más, de una vuelta a las operaciones fundadoras: es el paisaje como tierra explotada releído en clave política lo que acá se hace presente.

\section{La ciudad ausente}

Más allá de estas caracterizaciones espaciales sobre el territorio y la riqueza, interesa considerar la figuración urbana del cronista en la visión de Río Gallegos. Si la orilla social de Tuñón en su poesía es "el corazón ruinoso de Buenos Aires" (Stratta 1989: 187), este corazón ruinoso metropolitano (o de "cualquier ciudad"), ${ }^{16}$ pareciera constituirse en el telón de fondo de la representación de Santa Cruz; aquello que el escritor anhela en una aproximación inicial, pero no termina de encontrar en el espacio ciudadano del viaje a la Patagonia.

La segunda crónica refiere la perplejidad de esa falta; se enuncia desde una carencia que se vuelve productividad escrituraria y que tiene como contrapartida lo que abunda, por ejemplo, en sus textos poéticos previos, pero que aquí no aparece fácilmente: los transhumantes, la mezcla de geografías lejanas y cercanas, los puertos, los navíos, las rameras, los titiriteros, los vendedores de baratijas, los muelles, las mujeres, los cigarrillos, los almacenes, los libros, los entretenimientos baratos, los teléfonos: ${ }^{17}$

Río Gallegos levanta un tímido caserío de cinc y madera, con una que otra construcción de ladrillo salpicando el paisaje gris. Ciudad lampiña, laboriosa y tranquila no encontramos en ella ni el dancing internacional ni el recodo de la aventura extraordinaria... [...]

...y los hombres oscuros y silenciosos beben en los boliches desparramados entre el largo caserío. Se trabaja demasiado y hay que pensar en sortear los elementos desencadenados (González Tunón 1932b: 9).

Las calles de una ciudad que hay en cualquier ciudad, menos en Río Gallegos, un "pueblecito gris y desolado", allí el cronista lee atraso. La representación de esta urbe "lampiña", de tímidos caseríos", "aterida y monótona", cuya lejanía invita "a pensar que todos los caminos del mundo se han cerrado", justifica el reclamo de una línea aérea austral que, en nexo con lo metropolitano, rompa la monotonía y ponga al poblado en contacto con el mundo. Es la esperanza que se dibuja cuando “cada sábado, un avión viene del horizonte". González Tuñón vuelve una vez más

\footnotetext{
${ }^{15}$ Y agrega luego: "Subvenciones no muy elevadas, caminos transitables, rebaja de los arrendamientos y los fletes, medios, implementos agrícolas, inmigrantes europeos, promesas que se cumplan y una hábil y amplia acción de la Dirección de Tierras, harían de la Patagonia el soñado paraíso de la riqueza nacional" (González Tuñón 1932a: 9)

${ }^{16}$ Hago referencia a la expresión de González Tunón en el primer verso de su célebre poema "La calle del agujero en la media": "Yo conozco una calle que hay en cualquier ciudad" (González Tuñón 1993: 69).

${ }^{17}$ Menciono en esta lista algunos de los términos que enumera Martín Prieto para caracterizar el "registro material de los hechos, las cosas y las personas" que aparece claramente en la poesía de Tunón hasta Todos bailan (Prieto 2006: 237).
} 
a la argumentación que motivó el viaje y las corresponsalías, ahora a partir de las carencias figuradas de la ciudad.

Como puede verse, son crónicas escritas con el trasfondo de lo que se multiplica en la primera poesía del escritor pero que, en el revés de la búsqueda periodística y su representación, finalmente, terminan por descubrir en Río Gallegos cierta atmósfera de lo que las "calles lampiñas" amenazaban no dar. Como sostiene el repórter de Crítica: "Mientras en los frigoríficos trabajan centenares de obreros [...] por el corredor del hotel [...] pasa la vida trashumante... Desfilan los cazadores de zorros y guanacos, los vendedores de pieles, los ovejeros, los pichincheros, los aventureros, los hombres que vienen de todas las latitudes". Y añade: "Traen una especie de perfume de distancia, de polvo de horizonte" (González Tuñón 1932a: 9. Énfasis mío). Se trata del trabajo de la imaginación poética puesto al servicio de la crónica, o lo que puede pensarse como una interferencia sutil de periodismo y poesía. La mirada urbana del cronista trasladada a Santa Cruz (conformada según la perspectiva de ciudades más metropolitanas) establece las pautas no solamente de lo representado y figurado de ese espacio, sino también de algunos de los sucesos referidos y de los personajes invocados; como cuando el escritor-periodista reencuentra en Río Gallegos los rasgos de una urbe que, si bien resulta descolorida, pálida, ausente (y saturada del esfuerzo del trabajo obrero que el escritor va a denunciar), conserva algo del carácter ruin, canalla y romántico de las calles de las ciudades que hay en cualquier ciudad:

El pueblo proletario, el trabajador extranjero, el aventurero, el hombre de paso, tienen en la noche de Río Gallegos el lugar infaltable en todos los pueblos del Sur, el apartado barrio del amor... En el dancing prostibulario, el áspero vino y la ginebra de porrón dirigen un país de humo y de miseria, por el que se abre paso la voz carrasposa, alcohólica y ronca del desencolado piano automático.

Afuera de la ciudad sureña, afuera del campamento, propicia al fullero y al contratista. Sin embargo no tiene el tipismo, la atmósfera canalla de las afueras de las grandes ciudades. No es el vicio bajo, el que los arrastra. Es la huída al "Cafard", a la intemperie, al viento terrible que araña las ventanas, esa gran voz de la sociedad patagónica, el viento (González Tuñón 1932b: 13).

Las notas de González Tuñón enuncian germinalmente lo que en "Blues de Río Gallegos", el poema publicado en Todos bailan, el escritor va a desarrollar. Porque si en las crónicas periodísticas se insiste en la extranjería de la Patagonia, un tópico reiterado, por lo demás, en la representación de este espacio, ${ }^{18}$ el carácter extranjero se intensifica en el poema y el Sur resulta, ahora, un territorio poroso para los cruces culturales y lo forastero. ${ }^{19}$ Así, a diferencia de las corresponsalías de Crítica, donde el puerto nunca es mencionado y Río Gallegos no pasa de ser un

\footnotetext{
${ }^{18}$ Como dice Osvaldo Bayer en La Patagonia rebelde, retomando estos lugares comunes tan transitados: "En general, la impresión que causa al argentino, es la de que el territorio de Santa Cruz no pertenece a nuestra Patria" (Bayer 2011: 6).

${ }^{19}$ Recuérdese el peso del espacio del puerto en el poemario de 1926 de González Tuñón, El violín del diablo. Allí el puerto propicia la aparición de una zona fronteriza, de mezcla cultural por la cual el sujeto poético puede volverse, en algún sentido, cosmopolita. Se trata de un cosmopolitismo marginal, o cosmopolitismo del margen social.
} 
pueblo con límites muy fijos que no se expone hacia el mar, en el "Blues" constituye, por lo contrario, una ventana referencial que conecta la poesía y el ámbito de la visión con lo exterior, lo fronterizo y lo extraño. La figuración de Río Gallegos se trasunta entonces en una marcada ciudad portuaria, y el tópico de la extranjería, en un espacio de pasajes y de confluencia con los materiales y temas del poeta del "alma canalla":

Este es el auténtico corazón de la soledad

y la mañana se ha tirado en el puerto

contra barcos alcohólicos, dormidos, fatigados,

que vienen de los países de los mapas gastados,

los alevosos asesinatos, las suntuosas pieles,

los jugadores fulleros y los zorros colorados. [...]

mi espectro ha recorrido los prostíbulos,

mi gran alma canalla, ha conversado con mujeres torpes

de roncas voces y de ojos rasgados,

que conocieron a Sebastián Elcano

(González Tuñón 1993: 160-161).

El viaje a la Patagonia se transforma en el poema y le permite al autor retornar a procedimientos insistentes en su producción poética previa. Sin embargo, no se trata solamente del exotismo realista del territorio patagónico y de su cruce de extranjeros; se trata, más bien, de una reescritura poemática que combina los rincones ruinosos y la denuncia obrera. No sin cierta tensión con los rasgos de su poesía anterior (menos política y combativa), los versos de Todos bailan insisten en la cuestión de la lucha huelguista y el conflicto de los frigoríficos, que en las notas del diario, como se verá, va a resolverse casi como la preocupación central: "Pero yo te envío mi amor a doce grados bajo cero / y la señorita del Correo no sabe nada, / mientras los obreros, / ah, los obreros envejecen en los frigoríficos / y las veletas, / ah, las veletas en los tejados rojos enloquecen / y en la calle ancha, / ah, en la calle ancha debe estar esperando la muerte" (González Tuñón 1993: 61).

\section{La Patagonia rebelde}

...la gran voz de la sociedad patagónica, el viento (González Tuñón)

Un sitio figurado que añora la ciudad, se aleja del desértico vacío y se trasunta en tierra prometida, en González Tuñón estas representaciones se combinan con cierto imaginario moldeado por los hechos históricos de la Patagonia trágica que el autor reescribe, al ofrecer documentos textuales sobre el presente de la cuestión obrera y el mundo del trabajo. El territorio adquiere entonces nuevas características y se hacen visibles "los contornos de un espacio en el que las contradicciones sociales, la ferocidad contra los hombres y la represión alcanzan su punto más alto" (Blengino 2005: 203). Las crónicas dejan de lado cierta narratividad evidente en un primer momento y ensayan, luego, la denuncia social, con estadísticas, testimonios, 
cifras y datos. Se pretende dar solidez, así, en el espacio de la prosa periodística, a una identidad autoral ligada con el compromiso político y social.

Aunque no haya menciones específicas, las notas de Crítica confluyen o se articulan en su denuncia testimonial, con algunos lugares comunes muy transitados en el conocido libro de José María Borrero, que también son sin duda tópicos culturales y referencias de época concretas. Como es sabido, Borrero edita en 1928 La Patagonia trágica, un texto de fuertes marcas periodísticas y recopilación de artículos de diarios, en muchos casos de su autoría más o menos encubierta. ${ }^{20} \mathrm{Se}$ trata de la primera parte de un escrito de denuncia que, como sostiene el escritor Osvaldo Bayer, refiere "diversos episodios de matanzas de aborígenes" y denuncia "la explotación de los trabajadores rurales" por parte de los latifundistas de la región. El testimonio y la acusación se quedan en esa primera parte y el autor no avanza más, porque - añade Bayer-, si bien "Borrero prometió una nueva obra titulada Orgía de sangre en la que iba a detallar la masacre de los obreros del campo durante los movimientos huelguísticos de 1921-1922” en Santa Cruz, ese segundo libro, "por diversas circunstancias, nunca fue editado o tal vez ni siquiera escrito" (Bayer 2011: 5-6). ${ }^{21}$

Ahora bien, el objetivo del viaje enunciado en un comienzo por las corresponsalías de González Tuñón (hacer que el desierto no gane más la Patagonia por la supresión de la línea al Sur) termina desplazado. La defensa de la comunicación aérea a Santa Cruz se convierte en mensaje político y de denuncia social: es la compleja situación obrera lo que el cronista-testigo va a privilegiar en sus referencias al "grave" problema de los trabajadores en Río Gallegos:

En cuanto a los obreros: toda voz de protesta es acallada, toda rebeldía termina con la expulsión: los jornales son bastante reducidos y desde los trágicos días de los sucesos de Santa Cruz que culminaron con la muerte del coronel Varela -el caso de Wilkens- los oscuros obreros de esa región de la Patagonia se han resignado, aparentemente, a su suerte (González Tuñón 1932b: 9).

En una superposición que sobreimprime el cercano pasado huelguista y "los trágicos días de los sucesos de Santa Cruz" sobre el presente referido de la crónica, los artículos reactualizan esos acontecimientos de muerte y represión en el aquí y ahora del texto, casi sin juicios evaluativos sobre los protagonistas pretéritos (Varela, Wilkens). González Tuñón retoma, así, cierta preocupación que Crítica ya había esbozado sobre esos temas años antes, ${ }^{22}$ y su perspectiva en el diario insiste en la Patagonia como un espacio contradictorio y problemático, donde también en el momento de la escritura de las crónicas predomina la injusticia del trabajo obrero; una visión que sintoniza, ciertamente, con la que se pone en juego en el acalorado libro de Borrero. Las notas construyen de este modo un pretérito

\footnotetext{
${ }^{20}$ Para la cuestión del trabajo sobre la enunciación del testimonio en Borrero véase el estudio de Nofal.

${ }^{21}$ Como se sabe, es Bayer quien se propone escribir esa historia en La Patagonia rebelde, que constituye, como ha estudiado Rossana Nofal, un diálogo y una discusión reflexiva del texto de Borrero.

${ }^{22}$ En la cita transcripta figuran algunos de los nombres de los principales involucrados en los hechos (el teniente Varela que fuera asesinado por el anarquista Wilkens en represalia por la represión de los obreros). No obstante, González Tuñón no interviene con acusaciones o interpretaciones de los sucesos pasados sino para actualizarlos como iterativos en el presente: la situación no está resulta y esa es la razón principal por la que los obreros siguen sufriendo consecuencias trágicas y desafortunadas.
} 
iterativo que retorna sobre el presente y que moldea las circunstancias culturales, sociales e históricas que, sin cambios, permiten que hechos trágicos se repitan casi circularmente en el tiempo. En esta actualización de los sucesos de la "Patagonia sangrienta", la enunciación del viajero- escritor, conformada por disímiles discursos, politiza fuertemente su mirada y ofrece así un tipo de artículo periodístico que se acerca a algunas de las formas de la denuncia testimonial.

En efecto, en un sentido semejante a las operaciones textuales que se inscriben en el complejo libro de Borrero, González Tuñón arma un patchwork con testimonios y le da voz enfática a los trabajadores "acallados" y a los obreros. Conforma así un simulado pero elocuente diálogo ficticio (una simulación de oralidad) que se filtra en sus enunciados y en la narración de los hechos que transcribe de su informante Carlos Portela. Porque ciertamente, como sucede en el testimonio, en términos de Rosana Nofal, aquí se organiza un tipo genérico que se hace eficiente por la presencia escrituraria de una suerte de trascriptor prestigioso. Se trata, en este caso, de un cronista reconocido que además es periodista, poeta y escritor, que traduce la palabra ajena y les explica a los lectores porteños la compleja situación de Santa Cruz. "La escritura testimonial nunca es apócrifa; está autorizada por el 'prestigio' de instituciones letradas [...] y por una 'traducción técnica' de la voz del otro. El transcriptor construye un efecto de oralidad que facilita la transmisión del documento", sostiene Nofal. Es más, este tipo de texto propicia "un espacio tenso en el que narradores y narrados, desde posiciones desiguales, negocian un relato" (Nofal 1998: 1). Es por ello que el testimonio contrapone voces distintas, que en el caso de González Tuñón en estas notas, pasa por el filtro periodístico a través del cronista que es quien tamiza los informes que le proporciona Portela.

El poeta viajero, en tanto que cronista- traductor, informa y transcribe, educa y explica a los lectores del diario acerca de lo sucedido en "esas lejanías". El relato periodístico se presenta de este modo como un vehículo de unión en un territorio desintegrado y extranjerizante ("Gallegos recuerda otro país que no es el nuestro", sostiene el escritor). Efectivamente, la extraterritorialidad de la Patagonia, su mezcla de razas y culturas, su carácter foráneo a la Argentina, constituyen rasgos reiteradamente citados respecto de este espacio, que en José María Borrero aparecen vinculados con las dificultades y los abusos del trabajo obrero. En su texto se aúnan de manera indisoluble extranjería y explotación, en una visión que retomará, con claridad, el corresponsal de Crítica en su viaje a Santa Cruz:

La situación del obrero en las regiones patagónicas no ha variado, puede decirse, desde los sombríos días de los sucesos de Santa Cruz. La organización proletaria es un mito. Las huelgas no llegan a producirse por temor a las represalias patronales. Los que pretenden organizarlas son expulsados y condenados a las listas negras. Un frigorífico, una compañía explotadora cualquiera, no reconoce delegados y despide a los obreros que reclaman mejoras, aumentos de salarios, o que, simplemente, protestan por las frecuentes rebajas de aquéllos. En Santa Cruz, en cuyo frigorífico trabajan centenares de hombres, hemos podido comprobarlo. 
Por otra parte, los problemas de la desocupación, inmigración, épocas de "relache" y personal contratado en el exterior, han reagravado la situación del obrero patagónico (González Tuñón 1932d: 11).

O como se sostiene en otro lugar:

En verdad Río Gallegos parece la capital de un país que no es argentino. En las estancias prefiere a los obreros extranjeros. Hay muchos peones y muchos propietarios chilenos. Extranjeros que venden a extranjeros. La riqueza existe, se encuentra, pasa y se va. Claro está que una inmensa riqueza queda sin explotar en Santa Cruz, como en toda la Patagonia. Pero es que nadie se ha ocupado de ella... (González Tuñón 1932b: 9)

Más allá de la extranjería y de la falta de presencia del Estado, en la voz testimonial de González Tuñón también se denuncian, como en Borrero, las condiciones inhumanas de de la vida de los obreros, los salarios insuficientes y las circunstancias "crueles" del trabajo. Sus corresponsalías conforman de esta manera un doble mensaje que puede leerse, más allá del registro periodístico, como un ensayo político y social: que el desierto no gane otra vez la Patagonia y que la esclavitud y la sangre no se vuelvan nuevamente sobre el mundo obrero, para que el vacío desocupado, la ciudad ausente y la explotación del hombre por el hombre no dominen el territorio de Santa Cruz, ni se amenacen las expectativas de un futuro promisorio a medias conquistado por la ausencia del Estado nacional.

\section{Referencias bibliográficas}

Agamben, Giorgio, "El testigo", en Lo que queda de Auschwitz. El archivo y el testigo. Homo Sacer III. Valencia: Pre-Textos, 2000, pp. 8-21.

Bayer, Osvaldo. La Patagonia rebelde. Buenos Aires: Planeta, 2011.

Bernabé, Mónica, "Prólogo", en María Sonia Cristoff (comp.). Idea crónica: literatura de no ficción iberoamericana. Rosario/Buenos Aires: Beatriz Viterbo Editora/Fundación Typa, 2006, pp. 7-26.

Blengino, Vanni. La zanja de la Patagonia. Los nuevos conquistadores: militares, cientificos, sacerdotes y escritores. Buenos Aires: FCE, 2005.

Borrero, José María. La Patagonia trágica. Buenos Aires: Ediciones Continente, 2007.

Ferrari, Germán. Raúl González Tuñón periodista. Buenos Aires: Centro Cultural de la Cooperación Floreal Gorini, 2006.

González Tuñón, Raúl, "No dejemos que el desierto gane otra vez la Patagonia”, Crítica, 19 abr., 1932a, p. 9.

—-"Río Gallegos recuerda otro país que no es el nuestro", Crítica, 21 abr., 1932b, pp. 9 y 13.

—_La tierra es la cuestión madre en la Patagonia", Crítica, 22 abr., 1932c, p. 9.

- "El obrero de la Patagonia vive en malas condiciones", Crítica, 24 abr., 1932d, p. 11.

- La calle del agujero en la media/ Todos bailan. Buenos Aires: Espasa Calpe, 1933.

Juárez, Laura, "Raúl González Tuñón 'en las alas de Crítica'. Crímenes y 'aventuras' heroicas en la guerra del Chaco", Aletria: Revista de estudos de literatura, vol. 23, n. 1, Universidade Federal de Minas Gerais, Brasil, 2013, pp. 97-110. 
Livon-Grosman, Ernesto. Geografias imaginarias. El relato de viaje y la construcción del espacio patagónico. Rosario: Beatriz Viterbo Editora, 2003.

Nofal, Rossana, "Osvaldo Bayer, La Patagonia rebelde, la escritura de la memoria", Revista Interamericana de Bibliografía, n. 2, 1998, pp. 1-10.

Prieto, Martín, "La poesía realista y romántica de Raúl González Tuñón”, en Breve historia de la literatura argentina. Buenos Aires: Taurus, 2006, pp. 236-239.

Rodríguez, Fermín. Un desierto para la nación. La escritura del vacio. Buenos Aires: Eterna Cadencia, 2010.

Saítta, Sylvia. Regueros de tinta. El diario Crítica en la década de 1920. Buenos Aires: Editorial Sudamericana, 1998.

Sarlo, Beatriz, "La revolución como fundamento", en Una modernidad periférica. Buenos Aires: Nueva Visión, 1998, pp.121-154.

Silvestri, Graciela, "El imaginario paisajístico en el litoral y el sur argentinos", en Marta Bonuardo (dir.). Liberalismo, estado y orden burgúes (1852-1880). Buenos Aires: Sudamericana, 1999, pp. 217-292.

Stratta, Isabel y Graciela Speranza, "Girondo y González Tuñón: el vértigo de los viajes y la revolución", en Graciela Montaldo (ed.). Yrigoyen entre Borges y Arlt. Buenos Aires: Contrapunto, 1989, pp. 185-192.

Viñas, David, “Cinco entredichos con González Tuñón”, en Literatura argentina y política. De Lugones a Walsh. Buenos Aires: Sudamericana, 1996, pp. 168-179. 